\title{
Aplikasi Perdagangan Bitcoin Otomatis Berbasis Web
}

\author{
Paryanta $^{* 1}$, Budhi Sumboro ${ }^{2}$, Setiawan Nugroho ${ }^{3}$ \\ ${ }^{1}$ Program Studi Teknik Komputer, STMIK AUB, Surakarta, Indonesia \\ ${ }^{23}$ Program Studi Sistem Informasi, STMIK AUB, Surakarta, Indonesia \\ e-mail:*11paryanta@stmik-aub.ac.id ,2budhi.sumboro@stmik-aub.ac.id, ${ }^{3}$ stwnngrh@gmail.com
}

\begin{abstract}
Abstrak
Market place bitcoin adalah suatu bentuk pasar komoditas tempat bertemunya penjual dan pembeli bitcoin, meskipun tidak benar-benar berwujud seperti pasar yang biasa kita kenal. Akan tetapi, terdapat berbagai hambatan yang dapat mengganggu kenyamanan dan kestabilan profit saat trading manual di pasar bitcoin yaitu kurangnya pengalaman, tekanan psikologis, seperti rasa serakah, terlalu percaya diri, tidak sabar, emosi, dan juga trader harus terusmenerus di depan komputer untuk menjaga dan mengkontrol situasi di pasar.

Pembuatan aplikasi berisi tentang sistem trading menggunakan indikator Moving Average, Relative Strenght Index, dan Bollinger Bands. Aplikasi ini dibuat untuk di implementasikan dalam Website dengan bahasa PHP. AJAX yang diaplikasikan pada Aplikasi sekaligus sebagai Function agar data yang didapat secara realtime.

Hasil dari perancangan aplikasi ini telah tercipta sebuah aplikasi yang dapat membantu trader dan berguna untuk mempermudah kinerja trader di pasar bitcoin. Pengguna aplikasi ini adalah para user yang telah melakukan registrasi pada market place dengan membuka account, tidak terbatas pada trader pemula, juga trader professional.
\end{abstract}

Kata kunci-Bitcoin, EMA, RSI, BB, Trading, Profit

Bitcoin market place is a form of commodity market where sellers and buyers of bitcoin meet, though not really as tangible as the market we are familiar with. However, there are various obstacles that can interfere with the comfort and stability of profit when manual trading in the bitcoin market is lack of experience, psychological pressure, such as greed, overconfidence, impatience, emotion, and also traders must constantly in front of the computer to maintain and control the situation in the market.

The making of the application contains about the trading system using the Moving Average indicator, Relative Strenght Index, and Bollinger Bands. This application is made to be implemented in Website with PHP language. AJAX applied to the Application as well as Function for the data obtained in realtime.

The results of the design of this application has created an application that can help traders and useful to facilitate the performance of traders in bitcoin market. Users of this application are the users who have registered in the market place by opening an account, not limited to beginner traders, as well as professional traders.

Keywords-Bitcoin, EMA, RSI, BB, Trading, Profit 


\section{PENDAHULUAN}

Bitcoin adalah sebuah uang elektronik yang dibuat pada tahun 2009 oleh Satoshi Nakamoto. Nama tersebut juga dikaitkan dengan perangkat lunak sumber terbuka yang telah Satoshi Nakamoto rancang, dan juga menggunakan jaringan peer-to-peer tanpa penyimpanan terpusat atau administrator tunggal di mana Departemen Keuangan Amerika Serikat menyebut bitcoin sebuah mata uang yang terdesentralisasi. Bitcoin baru diciptakan dengan proses yang disebut "mining". Para miner menggunakan komputer canggih untuk menguraikan matematika kompleks untuk menemukan block baru Bitcoin, sebagai hadiahnya si penemu akan mendapat sejumlah bitcoin. Hadiah 1 block yang ditemukan awalnya ada 50 BTC (satuan mata uang bitcoin), sekarang 12,5 BTC/block, selanjutnya akan terus berkurang diiringi dengan bertambahnya sirkulasi Bitcoin. Sistem telah memastikan bahwa maksimal bitcoin yang beredar di dunia adalah 21 Juta BTC sehingga tidak akan terjadi inflasi. Sistem penciptaan Bitcoin yang terus berkurang setiap 4 tahun sekali ini menyerupai sistem ekonomi berdasarkan deflasi dan dengan makin terbatasnya supply bitcoin, harga bitcoin cenderung naik.

Perdagangan Bitcoin adalah proses jual-beli bitcoin dengan mata uang konvensional seperti rupiah. Bitcoin dapat diperjual-belikan di exchanger-exchanger seperti bitcoin.co.id (Indonesia), Coinbase (Amerika Serikat), Bittrex (Amerika Serikat), Bitfinex (Hong-Kong) dan Cex.io (Inggris). Selisih harga yang terjadi saat proses jual dan beli Bitcoin dapat menghasilkan keutungan. Harga Bitcoin dapat diprediksi dengan menggunakan analisis fundamental dan analisis teknikal. Analisis fundamental dapat dilihat dari isu-isu yang akan terjadi pada bitcoin seperti hardfork, regulasi dari pemerintah, dan peretas. Sedangkan analisis teknikal menitik beratkan pada pergerakan harga beberapa waktu sebelumnya untuk memprediksi harga di masa depan. Indikator yang sering digunakan dalam analisis teknikal adalah Relative Strength Index (RSI), Exponential Moving Average (EMA), dan Bollinger Bands (BB). Meskipun sudah menggunakan indikator-indikator tersebut, terkadang para trader terlambat dalam menentukan harga beli maupun jual.

Melihat kendala yang dialami oleh para trader bitcoin yang masih melakukan transaksi jual dan beli secara manual maka perlu adanya aplikasi yang dapat melakukan proses jual dan beli secara otomatis. Trader hanya perlu memasukan beberapa parameter yang diperlukan aplikasi agar dapat berjalan sesuai harapan. Aplikasi akan memproses beberapa indikator dan parameter yang telah ditetapkan untuk menentukan harga beli dan harga jual. Aplikasi mengambil langkah beli bitcoin disaat harga rendah dengan kecedurungan harga akan naik beberapa saat kemudian. Aplikasi juga akan otomatis menjual bitcoin diharga tinggi dengan kecenderungan harga akan turun beberapa saat kemudian. Dengan begitu trader tidak akan kehilangan momen untuk membeli dan menjual bitcoin yang dimiliki, karena dilakukan secara otomatis oleh aplikasi yang telah dibuat. Jika harga jual lebih tinggi dari harga beli maka trader bitcoin akan mendapatkan keuntungan dari perdagangan ini.

\section{METODE PENELITIAN}

Metode penelitian ini penulis melakukan berbagai tahapan yang berguna untuk meminimalisir kesalahan pada sistem aplikasi menggunakan metode waterfall. Penelitian tersebut mempunyai 5 tahap seperti Gambar 1. 


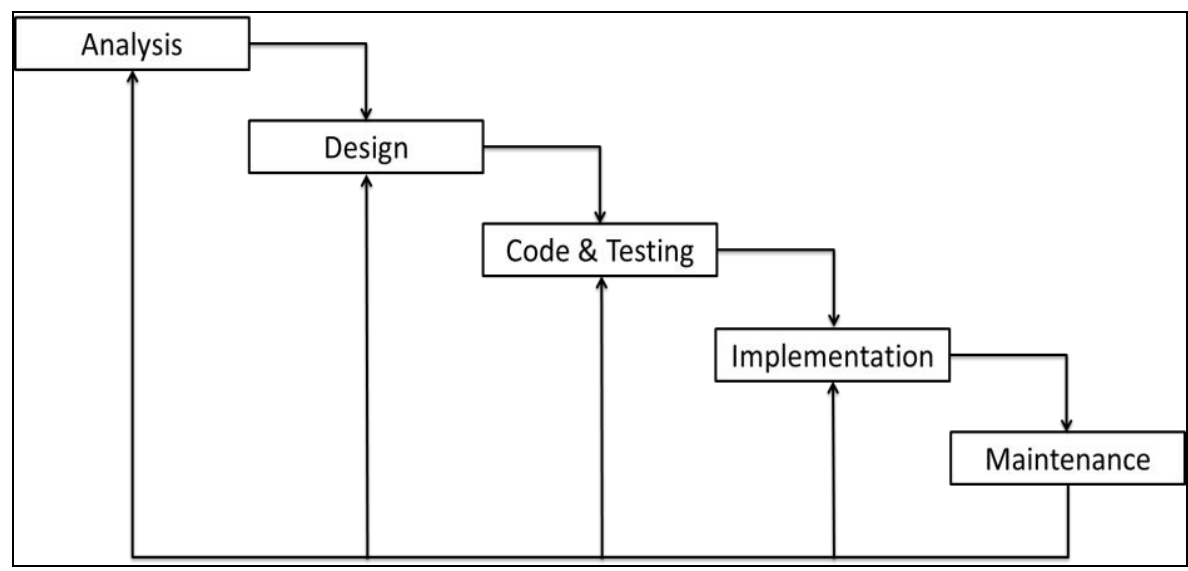

Gambar 1. Tahapan Metode Waterfall

\subsection{Analisa Sistem}

Untuk mengetahui kelemahan sistem lama maka penulis menggunakan metode analisa kelemahan sistem yang dikenal dengan metode PIECES. Sebagai alat ukur untuk menentukan sistem baru layak atau tidak untuk di gunakan dan harus mengalami peningkatan dari sistem lama yang terdiri dari enam aspek, yaitu:

a. Perfomance (Kinerja)

Proses transaksi sangat tidak efektif dari segi waktu dan analisa yang harus dilakukan.

b. Information (Informasi)

Informasi harga jual atau beli yang di dapat dari analysis fundamental masih tergantung pada trader lain dan kebenaranya masih sangat diragukan.

c. Economy (Ekonomi)

Secara ekonomi perdagangan secara manual sangat beresiko tinggi karena bisa mengakibatkan berkurangnya nilai aset.

d. Control (Keamanan)

Keamanan asset sangat bergantung dari proses jual-beli yang dilakukan dengan mengakses website.

e. Efficiency (Efisiensi)

Kurang efisien dikarenakan semua informasi teknikal di dapat secara manual dengan melakukan analisis candlestick dan sangat membuang waktu dan tenaga.

f. Service (Layanan)

Secara layanan website hanya menyadiakan indikator-indikator teknis tanpa memberikan sinyal jual atau beli.

\subsection{Analisa Kebutuhan Informasi}

Kebutuhan sistem informasi untuk Aplikasi Perdagangan Bitcoin Otomatis Berbasis Web dimana di dalamnya memuat informasi antara lain:

a. Informasi data pengguna meliputi nama, email, alamat bitcoin, saldo rupiah, dan saldo bitcoin.

b. Informasi harga bitcoin terkini, harga jual bitcoin terkini, harga beli bitcoin terkini, harga tertinggi bitcoin selama 24 jam terakhir, harga terendah bitcoin selama 24 jam terakhir, volume perdangan dalam satuan bitcoin, dan volume perdagangan dalam satuan rupiah.

c. Informasi order jual maupun beli yang sedang berlangsung meliputi tanggal melakukan order, harga yang ditentukan, jumlah transaksi yang dilakukan, dan tipe transaksi.

d. Informasi riwayat perdagangan yang telah dilakukan meliputi tanggal transaksi, tipe transaksi, harga, dan jumlah transaksi. 


\subsection{Perancangan Penelitian Metode Waterfall}

a. Requirements analysis and definition

Perancangaan penelitian ini di lakukan sebuah observasi secara langsung kepada trader bitcoin yang di ambil sample dua puluh orang untuk melakukan berbagai komentar dan tanggapan sulitnya melakukan analisis teknikal dalam menentukan harga jual atau beli dan meprediksikan pergerakan harga di masa depan.

b. System and software design

Setelah terkumpulnya berbagai informasi yang melalui proses observasi secara langsung kepada berbagai pihak terkait maka dibuatlah suatu aplikasi "Perdagangan Bitcoin Otomatis Berbasis Web".

c. Implementation and unit testing

Perancangan penelitian tahap berikutnya merancang sebuah kode - kode dalam aplikasi dan alur struktur sistem aplikasi yang telah dibuat menggunakan UML yang telah disaksikan oleh 5 trader bitcoin untuk melihat alur sistem yang akan dibuat dan digunakan.

d. Integration and system testing

Perancangan penelitian tahap berikutnya menguji program yang sudah jadi dan melakukan berbagai simulasi, untuk perwakilan trader di ambil 5 orang untuk melakukan pengujian program secara langsung.

e. Operation and maintenance

Pemeliharaan apliaksi dilakukan secara berkala dengan periode 3 bulan pemeliharaan yang selanjutnya akan berkala dan dibagikan secara free kepada trader bitcoin.

\subsection{Perancangan Flowchart Sistem}

Berikut flowchart sistem yang dibangun yang berguna untuk mengetahui alur kerja sistem tersebut, maka di buat flowchart sistem seperti Gambar 2.

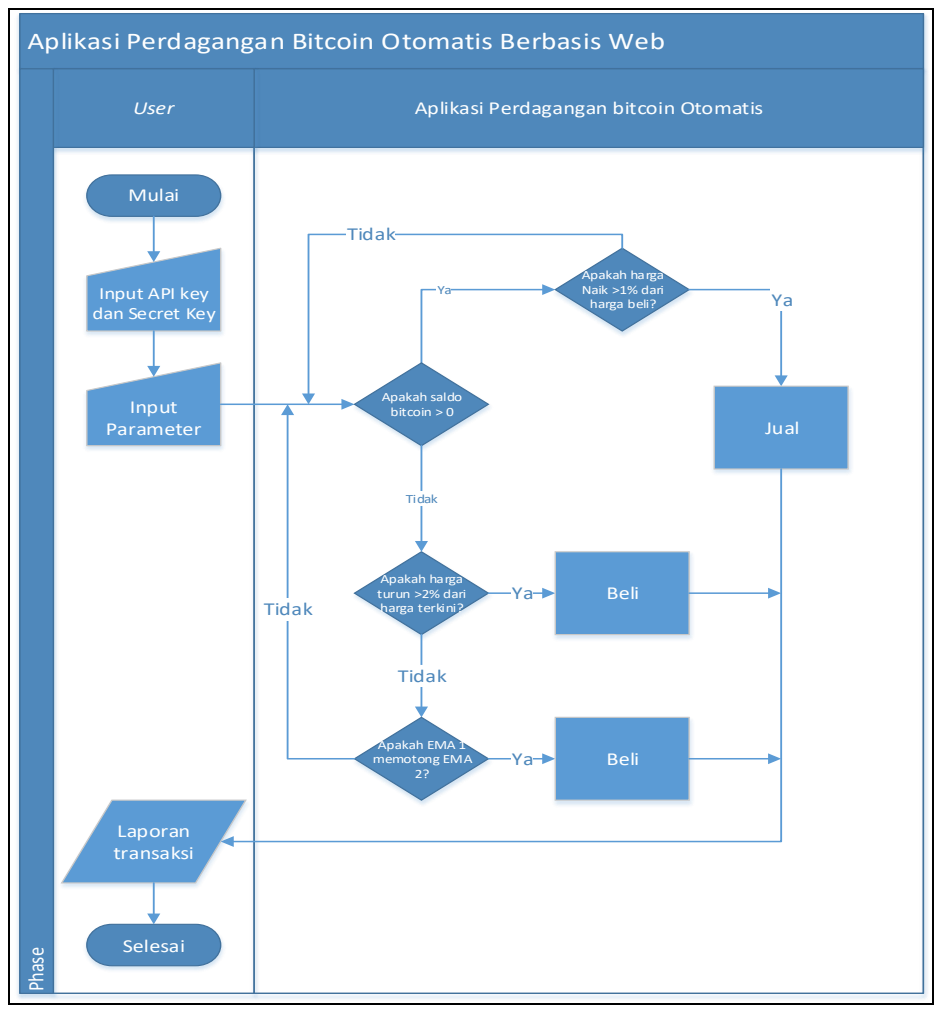

Gambar 2. Flowchart sistem 
Gambar 2 Flowchart sistem dimulai dari user yang menginputkan data API key dan parameter yang di teruskan di aplikasi untuk diolah datanya, aplikasi berjalan sesuai parameter yang telah dimasukan oleh user. Hasil dari proses aplikasi ini adalah laporan riwayat penjualan atau pembelian.

\subsection{Perancangan Class Diagram}

Diagram kelas (class diagram) adalah sebuah spesifikasi yang jika diinstansiasi akan menghasilkan sebuah obyek dan merupakan inti dari pengembangan dan desain berorientasi obyek. Class Diagram dapat dilihat pada Gambar 3.

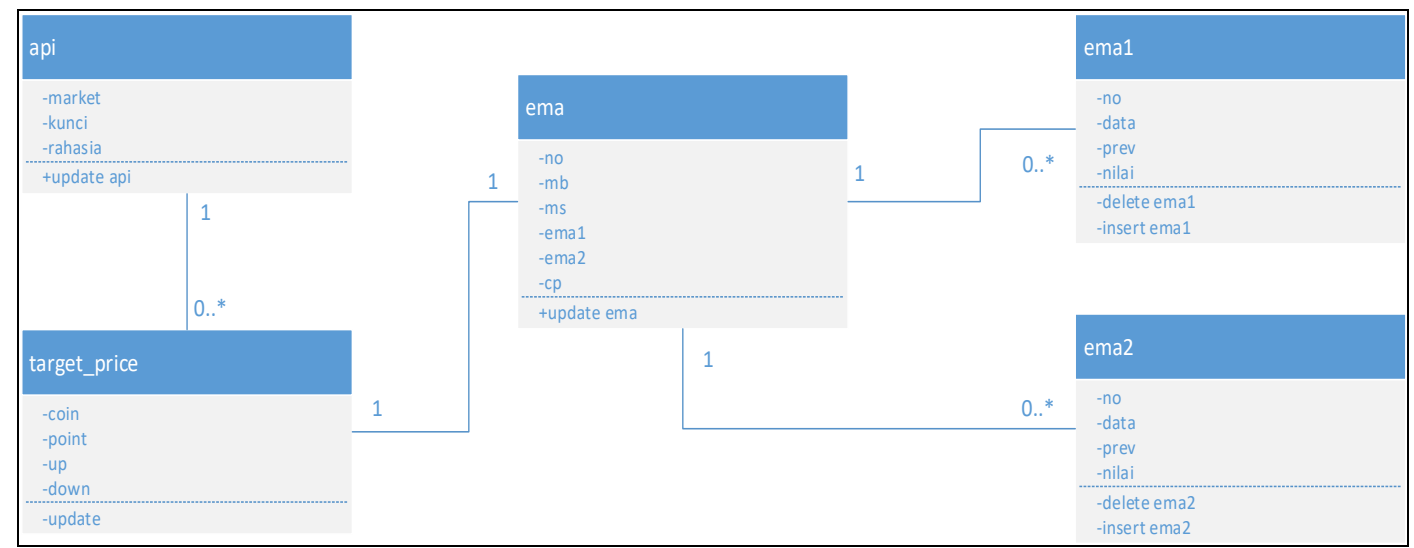

Gambar 3. Class Diagram

\subsection{Perancangan Interface / Antar Muka}

a. Halaman API key

Aplikasi perdagangan bitcoin otomatis ini terdapat halaman API key. Tampilan halaman API key ditunjukkan pada Gambar 4.

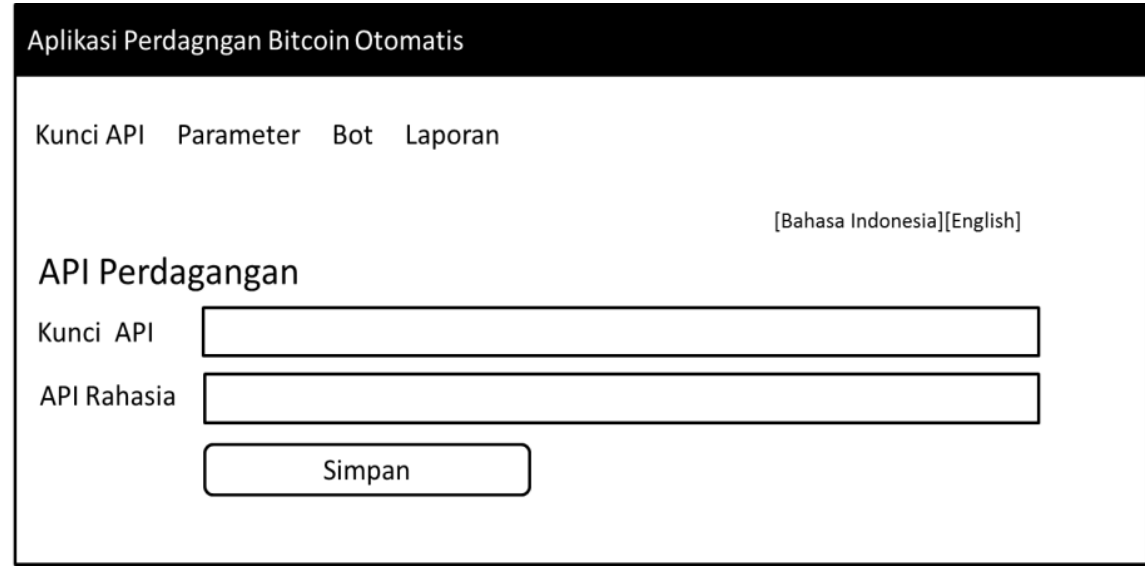

Gambar 4. Halaman API key

b. Halaman Parameter

Aplikasi perdagangan bitcoin otomatis terdapat halaman parameter. Halaman parameter dapat di lihat pada Gambar 5. 


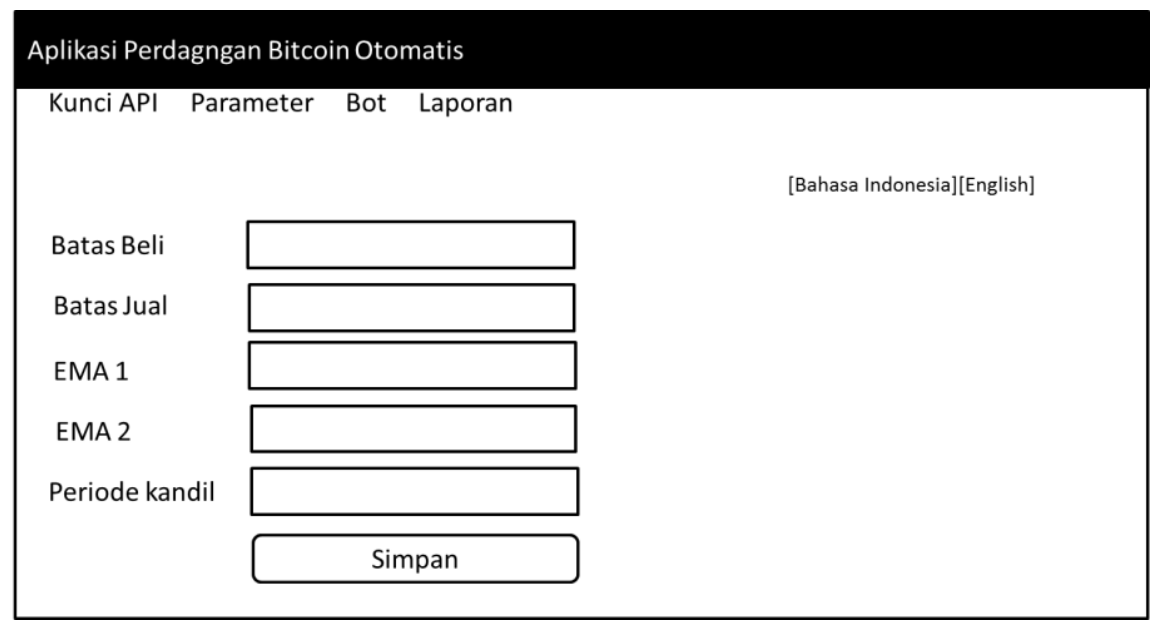

c. Halaman Bot

Gambar 5. Halaman parameter

Halaman bot ini adalah inti dari aplikasi perdagangan bitcoin otomatis ini. Tampilan halaman ini terdapat informasi data pengguna, harga bitcoin terkini, order yang dilakukan dan transaksi yang telah selesai dilakukan. Tampilan halaman bot dapat di lihat pada Gambar 6 .

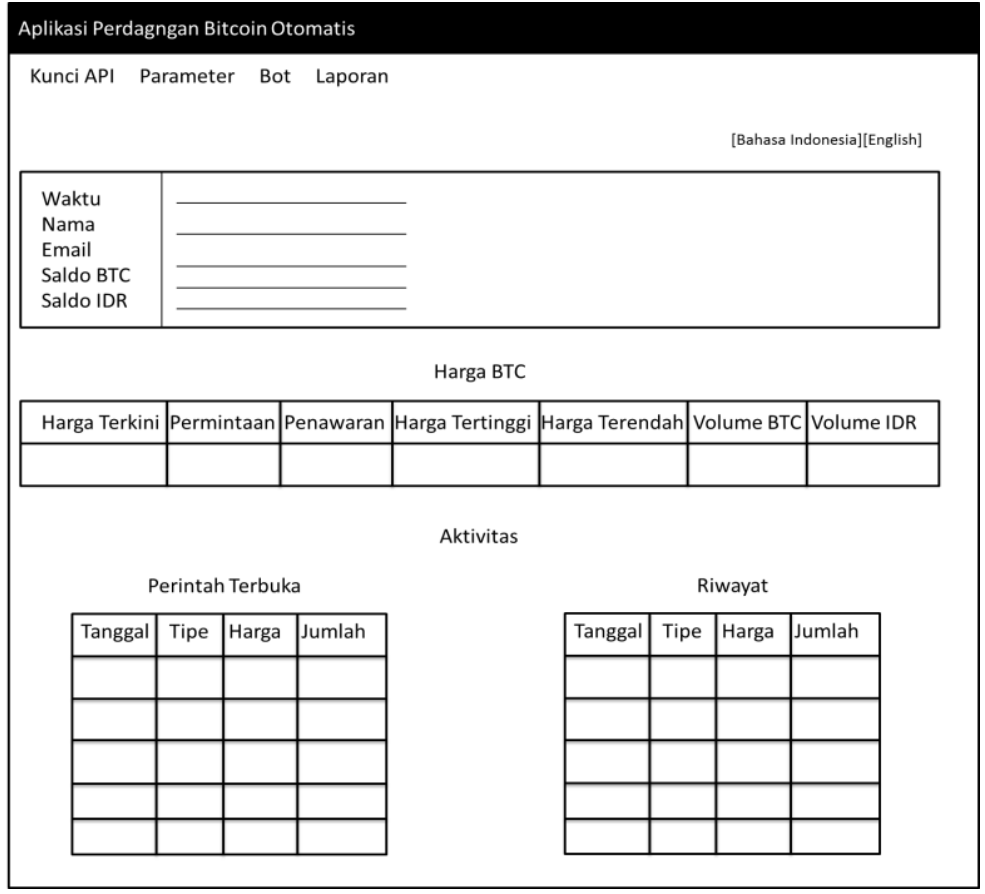

Gambar 5. Halaman Bot

d. Halaman Laporan

Tampilan halaman laporan dapat dilihat pada Gambar 6. 


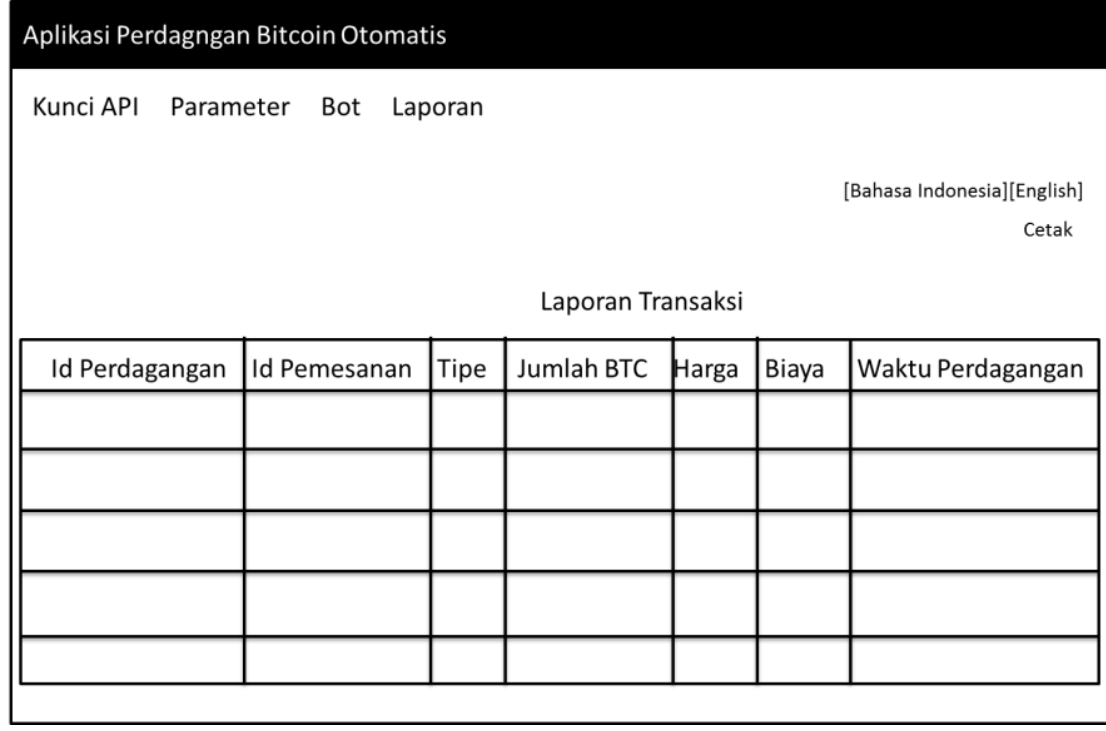

Gambar 6. Halaman Laporan

Pada gambar 6 halaman laporan adalah halaman yang menampilkan semua riwayat transaksi yang telah dilakukan.

\section{HASIL DAN PEMBAHASAN}

Uji coba sistem dilakukan menggunakan metode pengujian blackbox. Berikut merupakan pengujian blackbox pada beberapa menu pada sistem.

3.1 Pengujian API key

Tabel 1. Hasil pengujian API key

\begin{tabular}{|c|c|c|c|c|}
\hline \multirow{2}{*}{ Form Uji } & \multirow{2}{*}{ Butir Uji } & \multicolumn{2}{|l|}{ Hasil } & \multirow{2}{*}{ Hasil akhir } \\
\hline & & Diharapkan & Uji & \\
\hline \multirow[t]{2}{*}{ API key } & $\begin{array}{l}\text { Mengisi API key dan } \\
\text { secret key sesuai dengan } \\
\text { data dari bitcoin.co.id }\end{array}$ & $\begin{array}{l}\text { Sistem menerima } \\
\text { API key dan tampil } \\
\text { parameter }\end{array}$ & $\begin{array}{l}\text { Sudah } \\
\text { Terukur }\end{array}$ & Benar \\
\hline & $\begin{array}{l}\text { Mengisi API key dan } \\
\text { secret key tidak sesuai } \\
\text { dengan } \\
\text { bitcoin.co.id atau hanya } \\
\text { Mengisi salah satu } \\
\text { textbox }\end{array}$ & $\begin{array}{l}\text { Sistem menampilkan } \\
\text { pesan kesalahan }\end{array}$ & $\begin{array}{l}\text { Sudah } \\
\text { Terukur }\end{array}$ & Benar \\
\hline
\end{tabular}

\subsection{Pengujian Parameter}

Tabel 2. Hasil Pengujian Parameter

\begin{tabular}{|l|l|l|l|l|}
\hline \multirow{2}{*}{ Form Uji } & \multicolumn{2}{|c|}{ Butir Uji } & \multicolumn{1}{|c|}{ Hasil } & Hasil akhir \\
\cline { 2 - 5 } Parameter & $\begin{array}{l}\text { Mengisi margin buy, } \\
\text { margin sell, ema1, } \\
\text { ema2, dan candlestick } \\
\text { period. }\end{array}$ & $\begin{array}{l}\text { Sistem menerima } \\
\text { parameter dan tampil } \\
\text { bot }\end{array}$ & $\begin{array}{l}\text { Sudah } \\
\text { Terukur }\end{array}$ & Benar \\
\cline { 2 - 5 } & $\begin{array}{l}\text { Mengisi margin buy, } \\
\text { margin sell, emal, } \\
\text { ema2, dan candlestick } \\
\text { period dengan tidak } \\
\text { mengisi salah satu } \\
\text { textbox }\end{array}$ & $\begin{array}{l}\text { pesan kesalahan } \\
\text { Terukur }\end{array}$ & Benar \\
\hline
\end{tabular}




\subsection{Pengujian Bot}

Tabel 3. Hasil Pengujian Bot

\begin{tabular}{|c|c|c|c|c|c|}
\hline \multirow{2}{*}{\multicolumn{2}{|c|}{ Form Uji }} & \multirow{3}{*}{$\begin{array}{c}\text { Butir Uji } \\
\text { Function ticker }\end{array}$} & \multicolumn{2}{|c|}{ Hasil } & \multirow{3}{*}{$\begin{array}{l}\text { Kesimpulan } \\
\text { Benar }\end{array}$} \\
\hline & & & \multirow[b]{2}{*}{\begin{tabular}{l}
\multicolumn{1}{c}{ Diharapkan } \\
Sistem \\
menampilkan \\
harga bitcoin \\
terkini, jual \\
terkini, beli, \\
terkini, harga \\
tertinggi, harga \\
terendah dan \\
volume
\end{tabular}} & \multirow{2}{*}{$\begin{array}{c}\text { Uji } \\
\text { Sudah } \\
\text { Terukur }\end{array}$} & \\
\hline Bot & 1 & & & & \\
\hline & 2 & Function balance & $\begin{array}{l}\text { Sistem } \\
\text { menampilkan } \\
\text { nama, email, } \\
\text { alamat bitcoin, } \\
\text { saldo rupiah, } \\
\text { saldo bitcoin. }\end{array}$ & $\begin{array}{l}\text { Sudah } \\
\text { Terukur }\end{array}$ & Benar \\
\hline & 3 & $\begin{array}{l}\text { Function open } \\
\text { order }\end{array}$ & $\begin{array}{l}\text { Sistem } \\
\text { menampilkan } \\
\text { order yang } \\
\text { masih berjalan } \\
\text { dan belum } \\
\text { terselesaikan. }\end{array}$ & $\begin{array}{l}\text { Sudah } \\
\text { Terukur }\end{array}$ & Benar \\
\hline & 4 & Function history. & $\begin{array}{l}\text { Sistem } \\
\text { menampilkan } \\
\text { riwayat } \\
\text { transaksi }\end{array}$ & $\begin{array}{l}\text { Sudah } \\
\text { Terukur }\end{array}$ & Benar \\
\hline
\end{tabular}

\subsection{Pembahasan}

Pada Aplikasi Perdagangan Bitcoin Otomatis Berbasis Web terdapat halaman API key dengan nama halaman "index.php", halaman API key dapat dilihat pada Gambar 7.

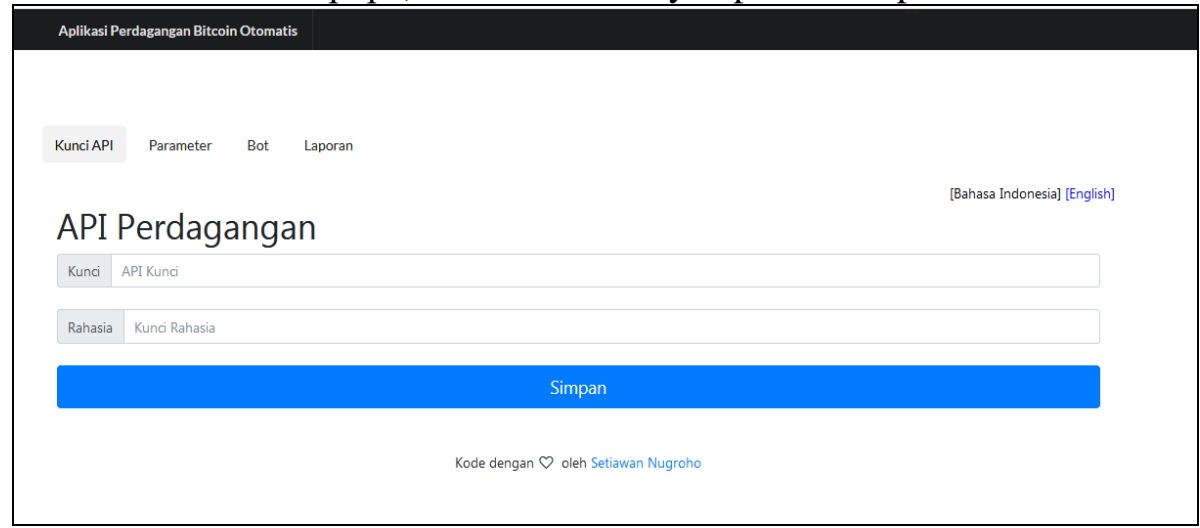

Gambar 7. Halaman API key

Halaman API key berfungsi sebagai langkah pertama untuk masuk ke dalam Aplikasi Perdagangan Bitcoin Otomatis Berbasis Web. Pada halaman parameter berfungsi untuk memasukan parameter yang digunakan sebagai acuan aplikasi berjalan seperti pada Gambar 8 . 


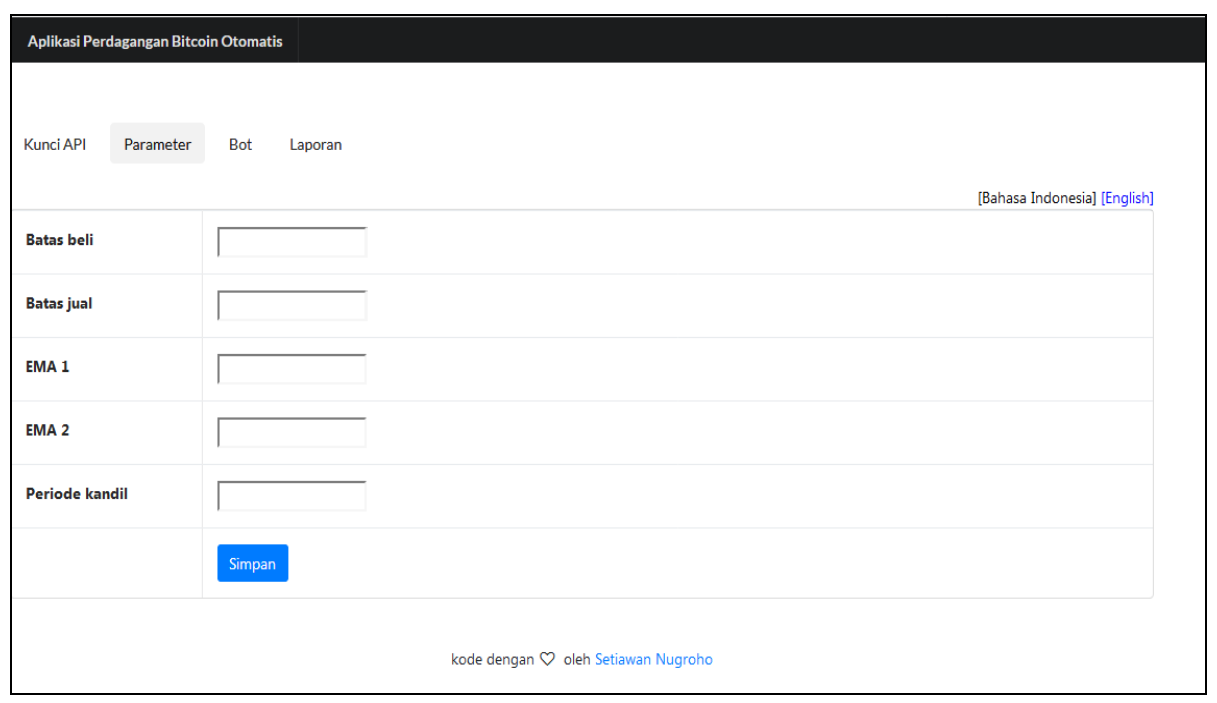

Gambar 8. Halaman Parameter

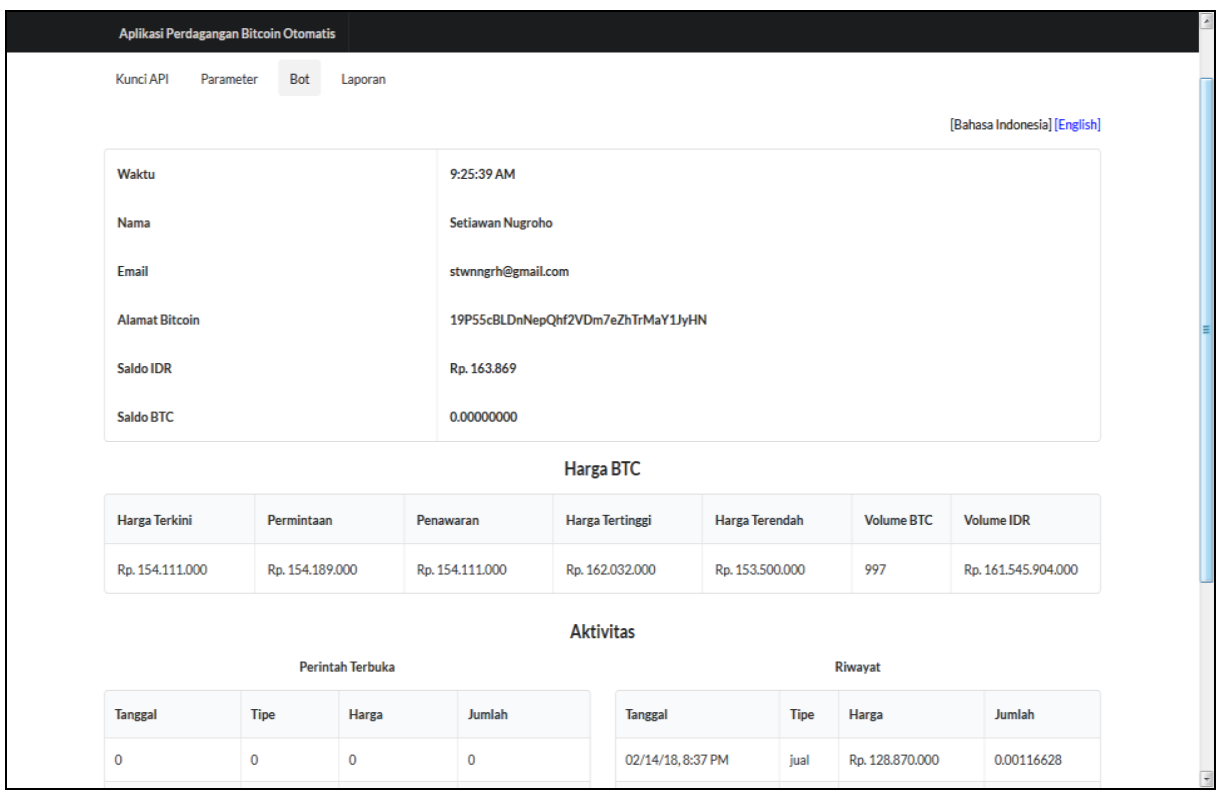

Gambar 9. Halaman Bot

Halaman bot berfungsi sebagai tampilan aplikasi melakukan proses jual-beli bitcoin. 


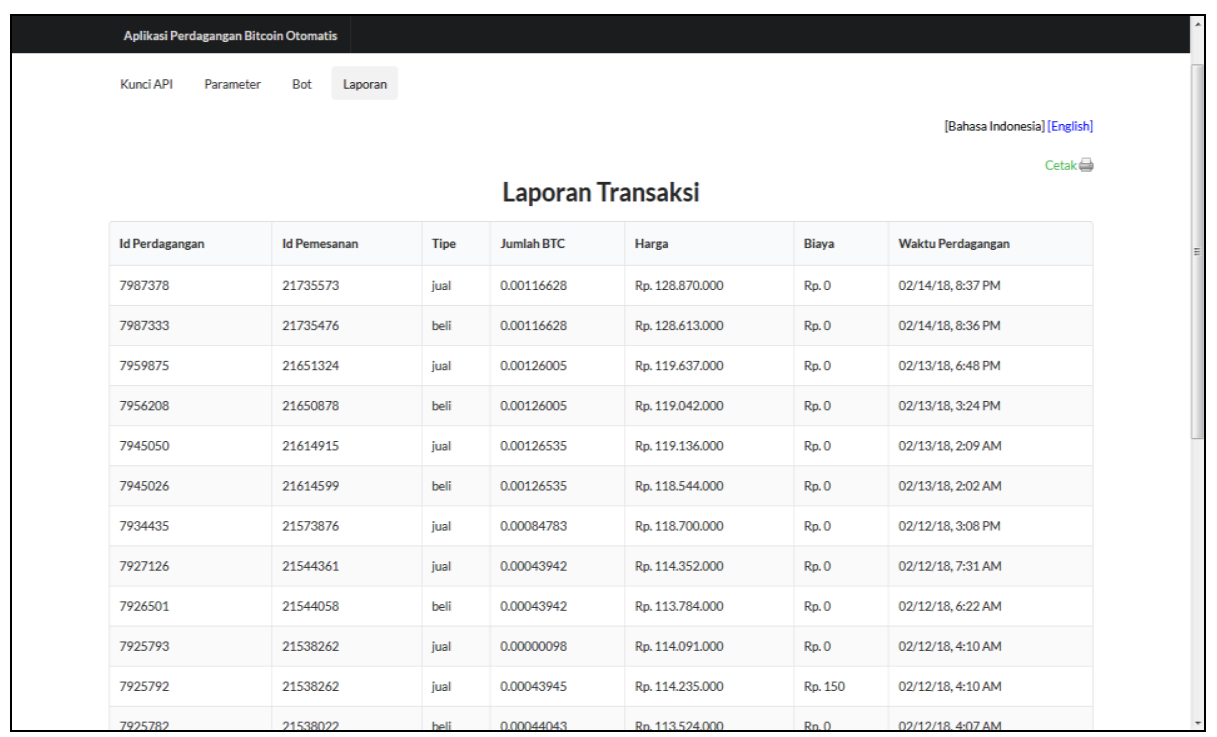

Gambar 10. Halaman laporan

Halaman laporan berfungsi untuk menampilkan riwayat transaksi yang telah dilakukan.

\section{KESIMPULAN}

Dalam pengembangan Aplikasi Perdagangan Bitcoin Otomatis berbasis Web dapat diambil kesimpulan sebagai berikut :

1. Perancangan dan pembangunan Aplikasi Perdagangan Bitcoin Otomatis berbasis Web dilakukan dengan menggunakan metode pengembangan sistem waterfall. Penulis melakukan analisa kebutuhan dengan melakukan observasi secara langsung dan melakukan wawancara terhadap trader bitcoin. Informasi yang telah didapat menjadi acuan dalam perancangan sistem yaitu meliputi Use Case Diagram, Class Diagram, Activity Diagram, Squence Diagram, Relasi tabel, HIPO kemudian penulis melakukan coding untuk menerjemahkan dalam bahasa yang bisa dikenali oleh komputer. Setelah pengkodean selesai maka dilakukan testing terhadap sistem menggunakan metode blackbox untuk menemukan kesalahan kesalahan pada sistem, kemudian dilakukan pengkajian ulang dan perbaikan terhadap sistem agar menjadi lebih baik.

2. Hasil pengujian perangkat lunak pada pembangunan Aplikasi Perdagangan Bitcoin Otomatis berbasis Web menyatakan semua butir uji pada kelas uji dan tingkat pengujian sistem dengan teknik pengujian blackbox menguji semua fungsionalitas aplikasi dari Aplikasi perdagangan bitcoin dinyatakan diterima dan telah terukur.

\section{SARAN}

Saran dalam pengembangan Aplikasi Perdagangan Bitcoin Otomatis berbasis Web ini masih dapat dikembangkan dengan harapan desain sistem yang lebih menarik yaitu sebagai berikut :

1. Fasilitas Cetak laporan per periode waktu.

2. Indikator ichiboku dalam mengambil langkah jual atau beli.

\section{DAFTAR PUSTAKA}

[1] Abdulkadir Muhammad, 2010. "Hukum perusahaan Indonesia", cet.4, Bandung: PT. Citra Aditya Bakti.

[2] Arif Syukur Setyawan. 2014. "Analisa Metatrader Dengan Menggunakan Software”. Surakata : Universitas Muhammadiyah Surakarta. 
[3] Danur Aji, Pratama 2014, Lintas text codding pemrogrman, Python application Programing Interface, Program lanjut basis codding.

[4] Darmawan, Oscar. 2017. "Bitcoin Trading For Z Generation" Jakarta: Jasakom.

[5] Deitel, Harvey M 2012. Javascript Education Person, Programing Module of Netherland vol 34, Indonesia Language.

[6] Hakim Lukmanul. 2004 "Cara Cerdas Menguasai Layout, Desain, dan Aplikasi" Yogyakarta : Andi Offset.

[7] Indrajani, dkk. 2010. "Analisis dan Perancangan Sistem Pemasaran Berbasis Web Pada PT. Dutadharma Utama”. Jakarta: Sistem Informasi Universitas Binus.

[8] Kusrini dan Andri Koniyo. 2007. "Tuntunan Praktis Membangun Sistem Informasi Akuntansi dengan Visual Basic \& Microsoft SQL Server". Yogyakarta: Andi.

[9] Mahavindra Dwi Firmansyah. 2015. "Implementasi Penggunaan Sistem Pakar Pada Trading Forex Jenis Locco". Semarang : Universitas Dian Nuswantoro.

[10] Nugroho, Adi. 2010. "Rekayasa Perangkat Lunak Berbasis Objek dengan Metode USDP”. Yogyakarta : Andi Offset.

[11] Pramana, Hengky W 2009. "Aplikasi mobile dan Ilmu Komunikasi berbasis Android". Sistem Informasi Barcode Otlet Berbasis Android Universitas Indonesia Jakarta.

[12] Praptiningsih. Yulia Eka. 2012. "Aplikasi Penyewaan Ruangan PT. Simaeru Indonesia Raya Dengan Visual Basic 6.0.” Depok: Universitas Gunadarma, UG Jurnal Vol. 6 No. 01, 2012.

[13] Pressman, Roger S. 2002 "Rekayasa Perangkat Lunak Pendekatan Praktisi” (Buku1). Edisi 2. Andi : Yogyakarta.

[14] Raharjo, Budi. 2011. "Membuat Database Menggunakan MySQL". Bandung : Informatika.

[15] Risma Widyawati. 2015. "Analisis Faktor-Faktor Yang Mempengaruhi Pergerakan Harga Bitcoin Periode 17 Agustus 2010-31 Desember 2014”. Surakata : Universitas Sebelas Maret.

[16] Rosa dan Shalahuddin, M. 2013. Rekayasa Perangkat Lunak Terstruktur

[17] Dan Berorientasi Objek. Informatika. Bandung

[18] Siswoyo, Sony. 2013. "Anaalisis Fundamental \& Teknikal Untuk Profit Lebih Optimal" Jakarta: PT. Gramedia Pustaka Utama.

[19] Sommerville, Ian. 2011. "Software Engineering (Rekayasa Perangkat Lunak)". Jakarta: Erlangga.

[20] Sugiyono. 2013. "Metode Penelitian Pendidikan, Kuantitatif dan Kualitatif”. Bandung: CV Alfabetha. 